\title{
Aquatic Biosystems reviewer acknowledgement 2013
}

Edward J Phlips ${ }^{1 *}$ and Shiladitya DasSarma²

\section{Contributing reviewers}

The Aquatic Biosystems editorial team would like to thank the following colleagues who contributed to peer review for the journal in 2013.

Javier Alcocer

Mexico

Kartik Baruah

Belgium

Zenon Batang

Saudi Arabia

\section{Donald Behringer}

United States of America

Peter Casper

Germany

Feng Chen

United States of America

Diógenes Felix da Silva Costa

Portugal

David Gauthier

United States of America

Baban Ingole

India

Luke Iwanowicz

United States of America

Jong-Myoung Kim

Korea, South

\author{
Miroslav Macek \\ Mexico \\ Ramon Massana \\ Spain
}

Maria Rosa Miracle

Spain

Uwe Münster

Finland

Rufus Kitto Muthunayagam

Saudi Arabia

Christopher Ottinger

United States of America

Wolf Pecher

United States of America

Danielle Puls

United States of America

\section{Nico Salmaso}

Italy

Terry Snell

United States of America

Luis Soto

Mexico
Evan Stephens
Australia

Gabriel Strain

United States of America

Sherry Tamone

United States of America

Amandine Vaslet

France

Andrea Waringer-Löschenkohl

Austria

Yik Sung Yeong

Malaysia

Author details

${ }^{1}$ Department of Fisheries and Aquatic Sciences, University of Florida, 7922 NW 71st Street,

Gainsville, FL 32653, USA. ²Department of

Microbiology and Immunology, Institute of

Marine and Environmental Technology, University of Maryland, 701 East Pratt Street, Baltimore, MD 21202, USA

doi:10.1186/2046-9063-10-1

Cite this article as: Phlips and DasSarma:

Aquatic Biosystems reviewer acknowledgement 2013. Aquatic Biosystems 2014 10:1.

\footnotetext{
* Correspondence: phlips@ufl.edu

${ }^{1}$ Department of Fisheries and Aquatic Sciences, University of Florida, 7922

NW 71st Street, Gainsville, FL 32653, USA

Full list of author information is available at the end of the article
} 